\title{
Journal of Animal and Poultry Production
}

Journal homepage: www.japp.mans.edu.eg

Available online at: www. jappmu.journals.ekb.eg

\section{Role of Spirulina Platensis as a Natural Antioxidant on in Vivo and In Vitro Embryo Development in Rabbits}

\author{
Nagy, W.M.*
}

Cross Mark

Animal Production Research Institute, Agricultural Research Center, Giza, Egypt

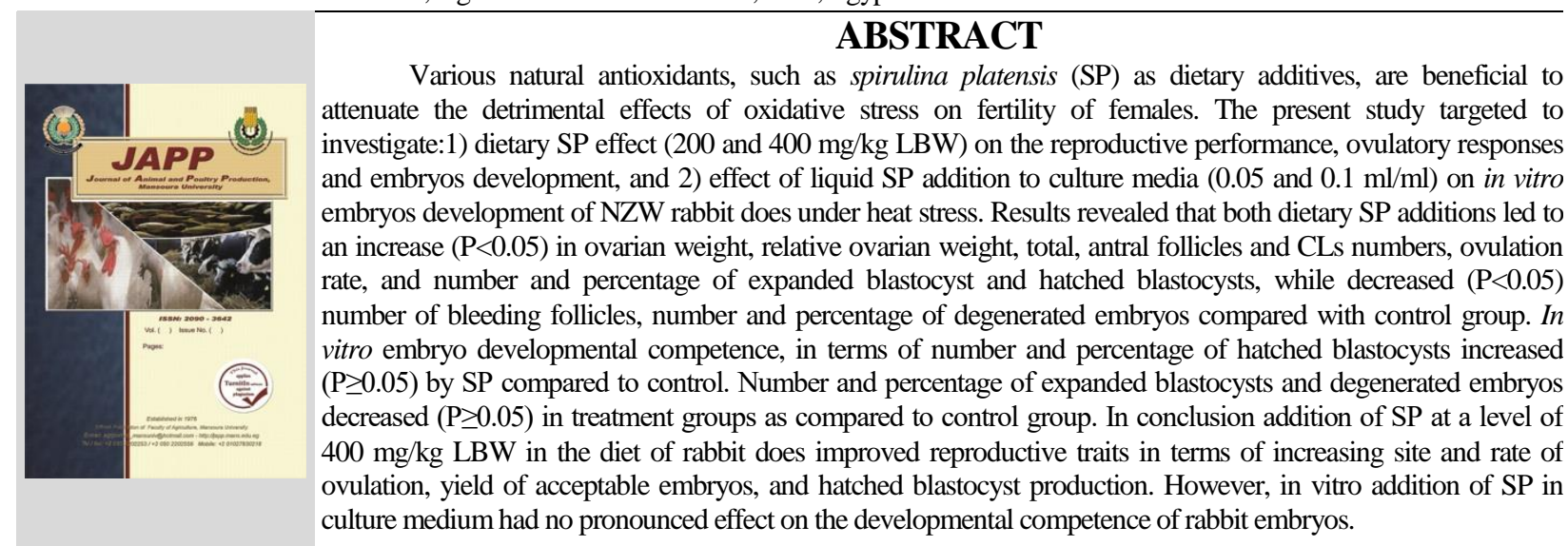

Keywords: Rabbit, blue-green algae, ovulation, embryo, hatched blastocyst

\section{INTRODUCTION}

In Egypt, rabbit production has an vital and important portion to solve the shortage in animal protein requirement. Egypt is located within the humid tropics with high temperature and humidity, in particular in the summer (Mousa-Balabel et al., 2017). Heat stress causes several changes in blood constituents and reproductive performance of rabbits (Zeweil et al., 2009; Abdel-Hamid et al., 2015), because rabbits are characterized by a comfortable zone ranging from 18 to $21^{\circ} \mathrm{C}$ (Fayez and Marai, 1994). Under high ambient temperature, the oxidative stress occurs by increasing reactive oxygen species (ROS) and other free radicals and reducing the cellular antioxidants (Ruder et al. 2009).

Exposing to heat stress condition causes a marked decrease in animal immunity and increasing of production of free radicals as well as lipid peroxidation of the cellular membranes (Mirzaie et al., 2018). Also, heat stress increases respiration rate, water intake, and corticosteroid levels, while decreases feed intake, and LH and FSH secretion, affecting the development of the ovaries and rate of ovulation (Chatterjee and Chatterjee, 2009; Arabameri et al., 2017). Moreover, the accumulation of oxidative damage under heat stress in distinct sub-cellular components, exerts impaired effects on DNA, proteins and lipids (Wang et al., 2017).

Under the normal environmental conditions, there are sufficient antioxidants against the free radical production (oxidants), of body metabolism. The oxidative stress occurs by exceeding oxidants production more than the capacity of body antioxidants (Roth, 2000). The simple strategy to inhibit the oxidation reactions is introduction of natural antioxidants in the diets (Botsoglou et al., 2004).

During in vitro fertilization ROS may increased and the collected gametes (oocyte quality, sperm function and, embryo development) may be impaired (Kiani-Esfahani et al. 2013; Lu et al. 2018; Agarwal et al. 2018). Excessive amount of ROS affects negatively influences the maturation and fertilization of oocytes (Agarwal et al. 2012; Wojsiat et al. 2017), together with a role in decreasing sperm motility, sperm number, and sperm-oocyte fusion (Cardoso et al., 2019), with deleterious impact on embryo development.

Enzymatic and dietary antioxidants are the major factors to prevent or inhibit the oxidative stress (Sikka et al. 1995). Non-enzymatic antioxidants, known as natural supplements in the diets, such as vitamins, minerals, and natural antioxidants, which have also biological effects (antiinflammatory, antibacterial, antiviral, anti-aging, and anticancer properties) (Xu et al. 2017).

Spirulina platensis (SP) is a photosynthetic, filamentous and blue-green algae and used as a dietary additives. It contains high level of protein (65-70\%), essential amino and fatty acids, vitamins, minerals, carotene and photosynthetic pigments (Farag et al., 2016). It is considering as a natural antioxidant having a positive role in attenuating the deleterious impact of oxidative stress on fertilization (Macedo et al., 2014; Mirzaie et al., 2018). Moreover, SP contains antioxidant compounds such as flavonoids, alkaloids, phenoles and steroids, which gave SP antioxidant, anti-inflammatory and immune modulatory properties and hypo-lipidemic action (Deng and Chow, 2010). Generally, SP stimulates the activity of antioxidant enzyme, and decrease the production of free

* Corresponding author. 
radicals, lipid peroxidation and DNA damage (Abdelkhalek et al., 2015; Anbarasan et al., 2011).

Therefore, the present study targeted to investigate the effect of Spirulina platensis on ovulatory responses and embryo development of heat stressed NZW rabbit does in Egypt. The effect of liquid SP addition to culture media at a level of 0.05 and $0.1 \mathrm{ml} / \mathrm{ml}$ on in vitro developmental competence of embryos of rabbit doe was also studied.

\section{MATERIALS AND METHODS}

This study was conducted at a private commercial rabbit farm, Mansoura City, Dakahlia Governorate, Egypt. The laboratorial work was carried out at Physiology and Biotechnology Laboratory, Animal Production Department, Faculty of Agriculture, Mansoura University, Egypt.

Animals

Healthy and adult New Zealand White (NZW) rabbit Does $\left(n=18\right.$ in the $1^{\text {st }}$ experiment and $n=18$ in the $2^{\text {nd }}$ experiment were used in this study. Average live body weight (LBW) and age of the experimental does were $3.05 \pm 0.22 \mathrm{~kg}$ and about 6 months of age. In a naturally ventilated and lighted rabbitry, does were housed individually in stainless steel cages batteries $(40 \times 50 \times 35 \mathrm{~cm})$ supplied with feeders and automatic fresh-water nipples.

Feeding system:

The experimental animals $(\mathrm{n}=36)$ were fed ad libitum on a commercial pelleted diet (17\% crude protein, $14 \%$ crude fiber and $2850 \mathrm{Kcal}$ digestible energy/ $\mathrm{kg}$ ), covering their daily nutritional requirements according to NRC (1977). Ingredients and chemical analysis of the commercial diet used in rabbit does feeding are presented in Table 1.

Table 1. Ingredients and chemical analysis of the diet fed to rabbit does in different experimental groups

\begin{tabular}{lc}
\hline Item & $(\boldsymbol{\%})$ \\
\hline Ingredient: & 30.0 \\
Clover hay & 18.0 \\
Soybean meal $(44 \%)$ & 24.6 \\
Wheat bran & 21.0 \\
Barley grain & 3.0 \\
Molasses & 1.0 \\
Limestone & 0.20 \\
DL-Methionine & 0.50 \\
Common salt & 0.15 \\
Minerals ${ }^{2}$ & 015 \\
Vitamins & 1.40 \\
Di-Calcium phosphate & 100 \\
Total & \\
Chemical analysis (on DM basis, $\%):$ & 93.15 \\
Organic matter & 18.15 \\
Crude protein & 10.19 \\
Crude fiber & 2.60 \\
Ether extract & 62.21 \\
Nitrogen free extract & 6.85 \\
Ash &
\end{tabular}

\section{Experimental design:}

The $1^{\text {st }}$ experiment: (In vivo study)

Total of 18 rabbit does were divided into three groups, six in each. A basal complete feed diet in pelleted form was used in feeding the control group (G1), while does in G2 and G3 were fed the same diet with oral administration with Spirulina platensis (SP) in amount of 200 and 400 $\mathrm{mg} / 10 \mathrm{ml}$ distilled water/doe, respectively. The treatment period of rabbit does was 30 days before mating.

\section{The $2^{\text {nd }}$ experiment: (In vitro study):}

All rabbit does $(n=18)$ were fed the commercial complete feed diet without any supplementation and kept under the same conditions of does in the $1^{\text {st }}$ experiment. These does were used as embryo donors.

Antioxidant and chemical analysis of Spirulina platensis:

The Spirulina platensis (SP) in powder form was obtained from Alga Biotechnology Unit, National Research Center, Dokki, Egypt. Nutritional analysis and active composition of SP is summarized in Table 2.

All analyses were performed at the Regional Centre for Food and Feed (RCFF), belonging to Agricultural Research Center, Ministry of Agriculture, Giza, Egypt. All analyses were expressed on the basis of $100 \mathrm{~g}$ edible portion of SP. The nutritional analysis of SP samples was determined according to AOAC (2006), while active antioxidant composition was determined according to AOAC (2000).

Table 2. Active antioxidant compounds and chemical analysis of Spirulina platensis.

\begin{tabular}{lc}
\hline Item & \\
\hline Antioxidant compounds: & \\
Vitamin E $(\mu \mathrm{g})$ & 110 \\
Total carotenoids $(\mu \mathrm{g})$ & 455 \\
$\beta$-carotene $(\mathrm{mg})$ & 220 \\
Chlorophyll $(\mathrm{mg})$ & 1.085 \\
Phycocyanin $(\mathrm{mg})$ & 11.65 \\
Superoxide dismutase $(\mathrm{IU})$ & 510.0 \\
Chemical composition $(\%$ on dry matter basis) \\
Crude protein & 55.8 \\
Crude fat & 6.2 \\
Crude fiber & 4.9 \\
Nitrogen free extract & 23.0 \\
Ash & 10.1 \\
\hline
\end{tabular}

\section{Experimental procedures:}

Mating:

In both experiments, all receptive does (with red vulva) were naturally mated with fertile bucks at a ratio of one male/ 3 females during $24 \mathrm{~h}$ as a mating period. In the $1^{\text {st }}$ experiment five conceived does out of 6 mated does, were taken from each group, transported to Laboratory and slaughtered $72 \mathrm{~h}$ post-mating._The conceived does were determined by the presence of corpora lutea (CLs) on their ovarian surface, then ovulatory response and embryo recovery were achieved. In the $2^{\text {nd }}$ experiment, does were slaughtered at $64 \mathrm{~h}$ post-mating to obtain embryos at morula stage.

Ovulatory response: (in vivo study)

Ovaries were isolated immediately after slaughter, then weighed and relative ovarian weight (ROW) to preslaughter weight was calculated. The antral follicles (AF), hemorrhagic follicles (HF), and CLs numbers were counted on the ovarian surface per dose. Also, ovulatory response in term of ovulation rate (OR) was computed as the following: $O R=($ No. of CLs/No. of HF and AF $) x 100$.

\section{Embryo recovery:}

Also, reproductive tract was separated and all ova (fertilized and unfertilized) were recovered from the slaughtered does by Flushing in Petri dishes with phosphate buffer saline (PBS) supplemented with $10 \%$ fetal calf serum (FCS) and gentamycin $(50 \mu \mathrm{g} / \mathrm{ml})$. The Petri dishes were examined by stereoscopic microscope for searching embryos (fertilized ova). These embryos were counted, then embryo recovery rate (ERR) was calculated as the following: ERR = No. of embryos/No. of CLs x100. The collected embryos were 
morphological evaluated after washing 3 times in PBS into acceptable and abnormal embryos according to El-Ratel and Gabr (2019).

Embryo culture: (in vitro study)

After slaughtering of does in the $2^{\text {nd }}$ experiment $64 \mathrm{~h}$ post-mating, embryos were recovered and only acceptable embryos $(n=45)$ at morula stage were taken. Embryos were cultured in control medium (M1) containing TCM-199 (100 ml) supplemented with $10 \%$ FCS and $50 \mu$ g gentamycin $/ \mathrm{ml}$. The control medium were supplemented with SP in liquid form (Alga Biotechnology Unit, National Research Center, Dokki, Egypt) at a level of $0.05 \mathrm{ml} / \mathrm{ml}$ (M2) or $0.1 \mathrm{ml} / \mathrm{ml}$ (M3). A total of 45 embryos were cultured M1, M2 and M3 (15 embryos in each) in $\mathrm{CO} 2$ incubator $\left(38.5^{\circ} \mathrm{C}\right.$, high humidity and $5 \% \mathrm{CO} 2$ in air) under mineral oil for 5 days for determining the developmental competence to embryos at blastocyst, expanded and hatched blastocyst stages.

Statistical analysis:

One-way ANOVA design (Completely randomized design) was used within the software package of SAS (2004) was used for the statistical analysis of the obtained data. The statistical model was $Y_{i j}=\mu+G_{i}+e_{i j}$, where $\mu=$ the overall mean, $\mathrm{G}_{\mathrm{i}}=$ group (1-3), and $\mathrm{e}_{\mathrm{ij}}=$ residual error. Duncan's multiple range test was used for separating the significant differences among means at $\mathrm{P}<0.05$ according to Duncan (1955).

\section{RESULTS AND DISCUSION}

Effect of in vivo Spirulina platensis treatment on: Ovulatory response:

Data shown in Table 3 clear that ovarian weight and relative ovarian weight were significantly $(\mathrm{P}<0.05)$ higher in treatment groups (G2 and G3) than in G1 (control). The effect of SP treatment on number of total and antral follicles was not significant, but this effect was significant on number of bleeding follicles, being significantly $(\mathrm{P}<0.05)$ lower in treatment groups than in control one. Treatment with SP increased number of CLs and ovulation rate but the differences were not significant.

It is of interest to note that increasing the absolute and relative ovarian weight was in association with increasing number of total follicles and CLs on the ovarian surface of does in treatment groups. Also, the ovulation rate was in a negative relationship with number of bleeding follicles, and positive with number of total follicles as affected by SP treatment (Table 3).

These results reflected positive impact of SP treatment on the ovulatory response of doe rabbits, being the highest for addition of $200 \mathrm{mg} / \mathrm{kg} \mathrm{LBW}$. In agreement with the present results, El-Ratel and Gabr (2019) reported that SP treatment showed marked increase in absolute and relative weight ovarian weight of rabbit does. This trend is in association with increase in number of CLs and decrease in number of follicles at different stage of development in treatment groups. In accordance with the present results, Mirzaiel et al. (2018) reported significant improvement in performance traits of broiler chickens fed diet supplemented with SP under heat stress as previously proved on reproductive parameters of does (El-Ratel, 2017) and mice (Pankaj, 2015) under normal conditions. Moreover, similar results of SP was reported on enhancing the ovulatory response by Abadjieva et al. (2018) in pigs and Nikodémusz et al. (2010) in birds.

Table 3. Effect of Spirulina platensis on ovulatory response and ovulation rate of does in the experimental groups.

\begin{tabular}{lllll}
\hline \multirow{2}{*}{ Item } & \multicolumn{3}{c}{ Experimental group } & P- \\
\cline { 2 - 4 } & G1 & G2 & G3 & Value \\
\hline
\end{tabular}

Doe weight $(\mathrm{kg}) \quad 3046.67 \pm 21.553041 .67 \pm 27.383060 .00 \pm 31.830 .890$

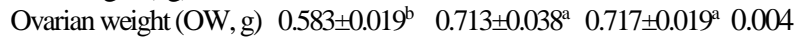

Relative OW (g kg-1) $\quad 0.019 \pm 0.0007^{\mathrm{b}} \quad 0.023 \pm 0.003^{\mathrm{a}} 0.023 \pm 0.0006^{\mathrm{a}} 0.008$

$\begin{array}{lllll}\text { Antral follicles/doe (n) } & 20.67 \pm 0.33 & 21.50 \pm 1.232 & 22.67 \pm 1.28 & 0.418\end{array}$

$\begin{array}{lllll}\text { Bleeding follicles/doe (n) } & 3.00 \pm 0.58^{\mathrm{a}} & 0.83 \pm 0.31^{\mathrm{b}} & 1.50 \pm 0.43^{\mathrm{b}} & 0.012\end{array}$

$\begin{array}{lllll}\text { Total follicles } & 23.67 \pm 0.760 & 22.33 \pm 1.145 & 24.17 \pm 1.195 & 0.462\end{array}$

$\begin{array}{lllll}\text { Corpora lutea/doe (n) } & 17.00 \pm 1.155 & 19.67 \pm 1.229 & 20.33 \pm 1.909 & 0.268\end{array}$

\begin{tabular}{lllll} 
Ovulation rate $(\%)$ & $72.01 \pm 47.88$ & $88.83 \pm 57.70$ & $84.74 \pm 75.43$ & 0.165 \\
\hline
\end{tabular}

Means denoted with different superscripts in the same row are significantly different at $\mathbf{P}<\mathbf{0 . 0 5}$.

Based on the obtained improvement in ovulation rate, antioxidant addition, in term of SP supplementation had a critical role in balancing the redox in supporting the normal function of the ovaries and embryonic development (Wang et al., 2017).

\section{Recovery and embryo production:}

Results in Table 4 indicated insignificant effect of SP treatment on embryo recovery rate, although it was higher in treatment groups than in control group. However, total number of embryos/doe, number and percentage of acceptable embryos, significantly $(\mathrm{P}<0.05)$ increased, while number and percentage of abnormal embryos significantly $(\mathrm{P}<0.05)$ decreased in treatment groups $(\mathrm{G} 2$ and $\mathrm{G} 3)$ as compared to the controls (G1). Similar results were observed by El-Ratel and Gabr (2019), who found that the embryo quality was improved by SP treatment than untreated groups, which may reflect positive effects of SP on in vitro embryo production.

Table 4. Effect of Spirulina platensis on recovery rate, and quantity and quality of embryos of does in the experimental groups.

\begin{tabular}{lllll}
\hline \multirow{2}{*}{ Item } & \multicolumn{3}{c}{ Experimental group } & P- \\
\cline { 2 - 4 } & G1 & G2 & G3 & Value
\end{tabular}

\begin{tabular}{llllll}
\hline Embryo recovery rate & $91.63 \pm 72.45$ & $97.50 \pm 93.11$ & $98.43 \pm 95.8$ & 0.52
\end{tabular}

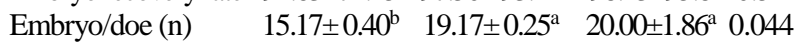

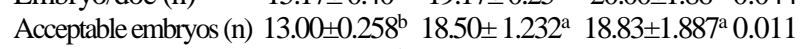

Acceptable embryos (\%) $86.13 \pm 33.64^{\mathrm{b}} \quad 96.56 \pm 18.19^{\mathrm{a}} \quad 93.88 \pm 17.22^{\mathrm{a}} 0.022$

$\begin{array}{lllll}\text { Abnormal embryos (n) } & 2.17 \pm 0.60^{\mathrm{a}} & 0.67 \pm 0.33^{\mathrm{b}} & 1.17 \pm 0.31^{\mathrm{b}} & 0.075\end{array}$

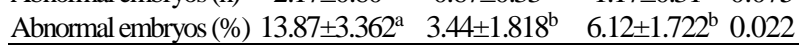

Means denoted with different superscripts in the same row are significantly different at $P<0.05$.

Embryonic stages:

Treatment of SP had insignificant effect on the number and percentage of embryos at expanded blastocyst stage. Meanwhile, number and percentage of hatched blastocysts were significantly $(\mathrm{P}<0.05)$ higher in treatment groups (G2 and G3) than in control one (G1). Number and percentage of degenerated embryos showed an opposite trend, being higher in control than in treatment groups, but this effect was significant $(\mathrm{P}<0.05)$ only on percentage of degenerated embryos (Table 5).

Our results are in agreement with data obtained by ElRatel and Gabr (2019) noting that the percentage of expanded and hatched blastocysts increased by SP treatment, while percentage of degenerated embryos decreased in all treatment groups as compared to control. 
Table 5. Effect of Spirulina on embryonic stage of does in the experimental groups.

\begin{tabular}{|c|c|c|c|c|}
\hline \multirow{2}{*}{ Item } & \multicolumn{3}{|c|}{ Experimental group } & \multirow{2}{*}{$\begin{array}{c}\mathbf{P}- \\
\text { Value }\end{array}$} \\
\hline & G1 & G2 & G3 & \\
\hline Expanded blastocyst (n) & $4.67 \pm 0.67$ & $5.33 \pm 0.62$ & $4.83 \pm 0.60$ & 0.74 \\
\hline Expanded blastocyst (\%) & $35.67 \pm 4.78$ & $29.21 \pm 3.48$ & $25.55 \pm 2.52$ & 0.18 \\
\hline Hatched blastocyst (n) & $5.50 \pm 0.34 \mathrm{~b}$ & $10.83 \pm 1.20 \mathrm{a}$ & $12.00 \pm 1.18 \mathrm{a}$ & 0.001 \\
\hline Hatched blastocyst (\%) & $42.40 \pm 2.81 \mathrm{~b}$ & $58.19 \pm 4.07 \mathrm{a}$ & $63.87 \pm 1.55 \mathrm{a}$ & 0.00 \\
\hline Degenerated (n) & $2.83 \pm 0.65$ & $2.33 \pm 0.49$ & $2.00 \pm 0.52$ & 0.58 \\
\hline Degenerated (\%) & $21.93 \pm 5.12 \mathrm{a}$ & $12.60 \pm 2.61 \mathrm{ab}$ & $10.58 \pm 2.32 \mathrm{~b}$ & 0.08 \\
\hline
\end{tabular}

It is well known that LH level reduction may impair rate of ovulation (Chatterjee and Chatterjee, 2009), fertility, developmental competence of embryos (Silva et al., 2013; Avila et al., 2016), implantation failure, embryo fragmentation, impaired placentation, and abortion by excessive ROS production (Agarwal et al., 2006).

Effect of SP treatment on in vitro embryo developmental competence:

After co-culture of embryos at morula stage for 5 days, the number and percentage of hatched blastocysts increased in treatment groups as compared to control (G1), but the differences were not significant. However, the effect of SP treatment on number and percentage of expanded blastocysts and degenerated embryos insignificant decreased in treatment groups as compared to control group (Table 6).

Table 6. Effect of Spirulina platensi addition in culture medium on in vitro developmental competence of embryos.

\begin{tabular}{lcccc}
\hline \multirow{2}{*}{ Item } & \multicolumn{3}{c}{ Experimental group } & P - \\
\cline { 2 - 5 } & G1 (control) & G2 (SP) & G3 (SP) & Value \\
\hline Normal (n) & 15 & 15 & 15 & - \\
Expanded blastocyst (n) & $7.67 \pm 0.89$ & $6.00 \pm 0.58$ & $5.67 \pm 0.33$ & 0.14 \\
Expanded blastocyst (\%) & $51.11 \pm 58.79$ & $40.00 \pm 38.49$ & $37.77 \pm 22.22$ & 0.14 \\
Hatched blastocyst (n) & $6.00 \pm 1.16$ & $7.33 \pm 0.88$ & $8.67 \pm 0.33$ & 0.17 \\
Hatched blastocyst (\%) & $40.00 \pm 7.70$ & $48.89 \pm 5.88$ & $57.78 \pm 2.22$ & 0.17 \\
Degenerated (n) & $1.33 \pm 0.33$ & $1.67 \pm 0.33$ & $0.67 \pm 0.33$ & 0.18 \\
Degenerated (\%) & $8.89 \pm 5.12$ & $1.11 \pm 2.61$ & $4.44 \pm 2.32$ & 0.18 \\
\hline
\end{tabular}

Recently, the usage of natural additives instead of synthetic vitamins must be put in attention towards animal production. Most compounds in natural sources of antioxidant is polyphenols, which have important physiological functions (Ebrahimzadeh et al., 2018). Female reproductive system is very sensitive to oxidative stress, then reduction in production and secretion of gonadotropins (LH and FSH) that are necessary for vital growth and development of ovarian follicles (Arabameri et al., 2017). Furthermore, a reduction in GSH of embryos, and elevation of ROS level leading to DNA damage were observed in in vivo heat stressed mice (Ozawa et al., 2002). Based on these findings, heat and oxidative stress are in a direct and indirect relationship with development of embryos.

In our study, the beneficial effects of SP addition may be in relation with improving the enzymatic antioxidants, which required for ovarian folliculogenesis, CLs formation, and embryo development. Also, SP as an antioxidant, acts as ROS scavenger contributing to maintain the luteal cell integrity and extension of CLs life span (Wang et al., 2017). Finally, SP contained several antioxidant compounds, such as carotenoids, chlorophyll, phycocyanin and superoxide dismutase (Table 2).
In conclusion addition of $400 \mathrm{mg} / \mathrm{kg} \mathrm{LBW}$ in the diet of rabbit does improved reproductive traits in terms of increasing site and rate of ovulation, yield of acceptable embryos, and hatched blastocyst production. However, in vitro addition of SP in culture medium had no pronounced effect on the developmental competence of rabbit embryos. Further studies needed for studying different levels of SP added to maturation, fertilization and embryo development

\section{REFERENCES}

Abadjieva, D.; Radka, N.; Yordan, M.; Gergana, J.; Mihail, Ch.; Julieta, D.; Almantas, Sh.; Aldona, Sh.; Katja, T. and Elena, K. (2018). Arthrospira (Spirulina) platensis supplementation affects folliculogenesis, progesterone and ghrelin levels in fattening prepubertal gilts. J. Appl. Phycol., 30: 445.

Abdel-Hamid, T.M. and Dawod, A. (2015). Impacts of ambient heat stress on growing rabbit performance and carcass traits. J. Vet. Sci. Technol., 2: 7.

Abdelkhalek, N.K.M.; Ghazy, E.W. and Abdel-Daim, M.M. (2015). Pharmacodynamic interaction of Spirulina platensis and deltamethrin in freshwater fish Nile tilapia, Oreochromis niloticus: Impact on lipid peroxidation and oxidative stress. Environ. Sci. Pollut. Res., 22: 3023.

Agarwal, A.; Aponte-Mellado, A.; Premkumar, B.J.; Shaman, A.; Gupta, S. (2012). The effects of oxidative stress on female reproduction: A review. Reprod. Biol. Endocrinol., 10: 49.

Agarwal, A.; Rana, M.; Qiu, E.; AlBunni, H.; Bui, A.D. and Henkel, R. (2018). Role of oxidative stress, infection and inflammation in male infertility. Andrologia, 50: 13126.

Agarwal, A.; Said, T. M.; Bedaiwy, M. A.; Banerjee, J. and Alvarez, J. G. (2006). Oxidative stress in an assisted reproductive techniques setting," Fertility and Sterility, 86:50.

Agarwal, A.; Said, T.M. (2003). Role of sperm chromatin abnormalities and DNA damage in male infertility. Hum. Reprod. Update, 9: 33.

Anbarasan, V.; Kumar, V.K.; Kumar, P.S. and Venkatachalam, T. (2011). In vitro evaluation of antioxidant activity of blue green algae Spirulina platensis. Int. J. Pharm. Sci. Res., 2: 2616.

AOAC. (2000). Official Methods of Analysis, 17th Ed. Association of Official Analytical Chemists, Inc. Washington, USA.

AOAC. (2006). Association of Official Analytical Chemist.13th Edition AOAC. Virginia Washington.

Arabameri, A.; Sameni, H. and Bandegi, A. (2017). The effects of propolis extract on ovarian tissue and oxidative stress in rats with maternal separation stress. Int J Reprod BioMed, 8: 509.

Avila, J.; Gonzalez-Fernandez, R.; Rotoli, D.; Hernandez, J. and Palumbo, A. (2016). Oxidative stress in granulosa-lutein cells from in vitro fertilization patients, Reproductive Sciences, 23: 1656.

Botsoglou, N.; Florou-Paneri, P.; Christaki, E.; Giannenas, I.; Spais, A. (2004). Performance of rabbits and oxidative stability of muscle tissues as affected by dietary supplementation with oregano essential oil. Arch. Animal Nutrition, 58 (3): 209. 


\section{J. of Animal and Poultry Production, Mansoura Univ., Vol. 11 (7) July, 2020}

Cardoso, J.P.; Cocuzza, M.; Elterman, D. (2019). Optimizing male fertility: Oxidative stress and the use of antioxidants. World J. Urol. 37: 1029.

Chatterjee, A. and Chatterjee, R. (2009). How stress affects female reproduction: An overview. Biomed. Res., 20: 79.

Deng, R. and Chow, T.J. (2010). Hypolipidemic, antioxidant and anti-inflammatory activities of microalgae Spirulina. Cardiovasc. Therapeut., 28: 33.

Ebrahimzadeh, S. K.; Navidshad, B.; Farhoomand, P. and Mirzaei Aghjehgheshlagh, F. (2018). Effects of grape pomace and vitamin $\mathrm{E}$ on performance, antioxidant status, immune response, gut morphology and histopathological responses in broiler chickens. South African Journal of Animal Science, 2: 324.

El-Ratel, I.T. (2017). Reproductive performance, oxidative status and blood metabolites of doe rabbits administrated with spirulina alga. Egypt. Poult. Sci., 37: 1153

El-Ratel, I.T. and Gabr, A.A. (2019). Effect of Spirulina and Vitamin $\mathrm{E}$ on Reproduction and in vitro Embryo Production in Heat-stressed Rabbits. Pakistan Journal of Biological Sciences, 22 (11): 545.

Farag, M.R.; Alagawany, M.; El-Hack, M.E.A. and Dhama, K. (2016). Nutritional and healthical aspects of Spirulina (arthrospira) for poultry, animals and human. Int. J. Pharmacol., 12: 36.

Fayez, I.; Marai, M.; Alnaimy, A. and Habeeb, M. (1994). Thermoregulation in rabbits. Proceedings of the $1^{\text {st }}$ International Conference on Rabbit Production in Hot Climates, Volume 8, September 6-8, 1994, Cairo, Egypt, pp: 33.

Kiani-Esfahani, A.; Bahrami, S.; Tavalaee, M.; Deemeh, M.R.; Mahjour, A.A.; Nasr-Esfahani, M.H. (2013). Cytosolic and mitochondrial ROS: Which one is associated with poor chromatin remodeling? Syst. Biol. Reprod. Med. 59: 352.

Lu, J.; Wang, Z.; Cao, J.; Chen, Y.; Dong, Y. (2018). A novel and compact review on the role of oxidative stress in female reproduction. Reprod. Biol. Endocrinol., 16: 80.

Macedo, D.; Tavares, L.; McDougall, G.J.; Miranda H.V. and Stewart, D. (2014). (Poly) phenols protect from"synuclein toxicity by reducing oxidative stress and promoting autophagy. Hum. Mol. Genet., 24: 1717.

Mirzaie, S.; Zirak-Khattab, F.; Hosseini S.A. and DonyaeiDarian, H. (2018). Effects of dietary Spirulina on antioxidant status, lipid profile, immune response and performance characteristics of broiler chickens reared under high ambient temperature. Asian-Aust. J. Anim. Sci., 31: 556.

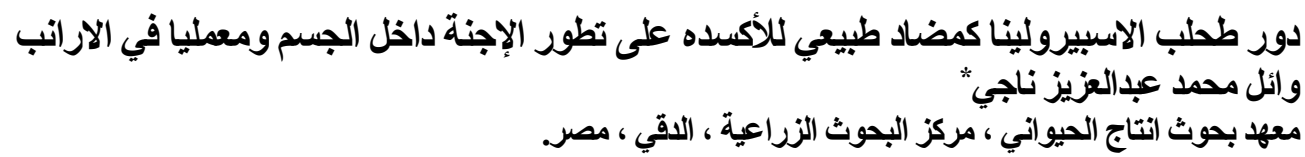

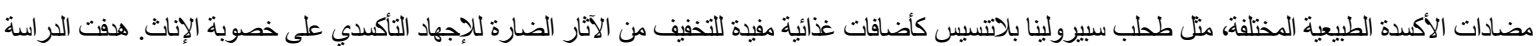

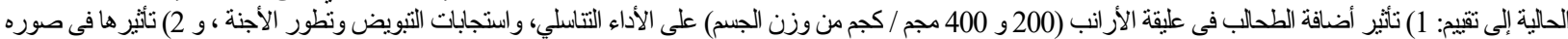

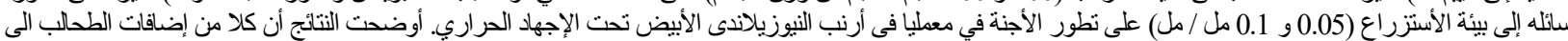

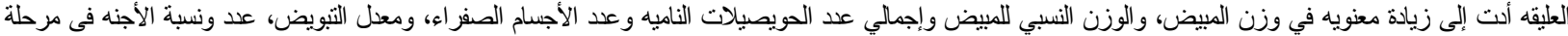

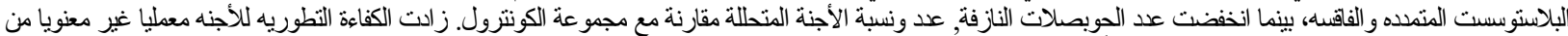

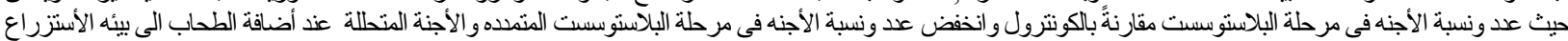

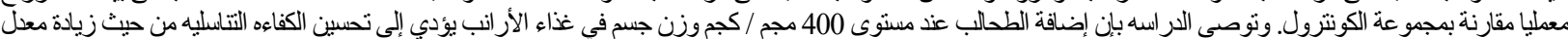

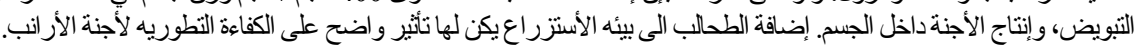

